\title{
A community study on the relationship of dental anxiety with oral health status and oral health-related quality of life
}

\author{
Sam K. S. Ng ${ }^{1,2}$, W. Keung Leung ${ }^{1}$ \\ ${ }^{1}$ Faculty of Dentistry, The University of Hong Kong, ${ }^{2}$ Department of Clinical Psychology, \\ Prince of Wales Hospital, Hospital Authority, Hong Kong SAR, China
}

Running Title: Oral health status, OHQoL, and dental anxiety

Corresponding author

W. K. Leung

Faculty of Dentistry, The University of Hong Kong, Room 3B39, Prince Philip Dental Hospital, 34 Hospital Road, Hong Kong SAR, China

Tel: $+852-2859-0417$

Fax: $+852-2858-7874$

E-mail: ewkleung@hkucc.hku.hk

Date of resubmission: April 4, 2007 
$\mathrm{Ng}$ SKS, Leung WK: A community study on the relationship of dental anxiety with oral health status and oral health-related quality of life. Community Dent Oral Epidemiol

\begin{abstract}
Objective: To investigate the relationship of dental anxiety with oral health status and oral-health related quality of life (OHQoL) among dentate subjects living in Hong Kong. Methods: 1000 Hong Kong residents who were aged 25 to 64 years and predominantly Chinese were asked to complete the Chinese short-forms of the Dental Anxiety Inventory (SDAxI) and Oral Health Impact Profile (OHIP-14S). Dental (DMFT index) and periodontal statuses (full-mouth clinical attachment level, CAL) were also assessed. Results: Ninety-six (9.6\%; mean SDAxI, 9.6), 799 (79.9\%; mean SDAxI, 15.0), and 105 (10.5\%; mean SDAxI, 27.4) participants had low, average, and high dental anxiety, respectively. The mean DMFT/CAL scores of each SDAxI subgroup were 8.5/1.4, 9.3/1.9, and 9.8/3.6, respectively. The corresponding mean OHIP-14S scores for each SDAxI subgroup were 4.0, 8.1, and 13.2, respectively. Post hoc analysis, adjusted for possible confounding factors, revealed statistically significant differences in DMFT and CAL scores in subjects with low versus high level of SDAxI, and significant differences in OHIP-14S scores between all 3 SDAxI categories. Conclusion: The trait disposition of dental anxiety may be a significant risk indicator of poor dental and periodontal status and is associated with a worse OHQoL.
\end{abstract}


Dental anxiety has been recognized as a significant health issue in many countries. A remarkable proportion of the population in the United States, the United Kingdom, the Netherlands, Denmark, Norway, Sweden, Hong Kong, and Canada reportedly have certain degrees of anxiety about dental visits and treatment (1-10). The general term "dental anxiety" might have diverse meanings in the dental literature (11), covering a rather wide range of emotions, from a relatively mild feeling of apprehension to extreme anxiety and dental phobia (12). Dental anxiety in the present study is defined as a situation-specific trait anxiety and as the disposition to experience anxiety in dental situations $(13,14)$. The terms "dental fear" and "dental anxiety" are interchangeable in the present context.

Researchers in dental anxiety have attempted to explore its causes, prevalence, and consequences. Some have also investigated its impact on the use of dental services and oral health status. The general perception is that dental anxiety can lead to avoidance behaviors, thereby resulting in lack of regular dental care and delay in seeking necessary treatment (1518). It is also widely assumed that avoidance behavioral patterns of dental care and treatment have a detrimental effect on dental health (19). These propositions appeared logical and intuitively appealing, even though studies of the relationship between dental anxiety and oral health status failed to yield indicative or conclusive findings.

Two studies have attempted to examine the association between self-reported dental anxiety and objective clinical indicators of oral health. Fearful dental patients reported that their dental and periodontal health were poorer than those of people of the same age $(19,20)$. Cohen (17) reported a possible association between scores on Corah's Dental Anxiety Scale (DAS) (21) and DMFS (decayed, missing, and filled surfaces) status in a rather restricted population of naval recruits consisting primarily of young men with relatively low rates of dental caries. Several other studies compared dental anxiety in edentulous and dentate subjects. 
A survey of dental fears, dental experiences, and perceived oral health status among 1,019 Seattle residents conducted by Milgrom et al. in 1988 (22) reported that high dental fear individuals perceived they had poor oral health status. The main concerns being the appearance of their teeth, they were more likely to report dental problems such as toothache or bleeding gums, and more likely to report a need for dental care. Similarly, Locker and Liddell (23) showed in a random sample of 580 people aged between 50 and 89 years that dentally anxious subjects were more likely than non-anxious ones to perceive a need for dental care, rate their oral health as poor, and report problems in chewing.

Schuurs et al. (24) and Locker et al. (25) found that mean DAS scores were higher in edentulous compared with dentated subjects, whereas Stouthard and Hoogstraten (26) found no differences in dental anxiety among edentulous and dentate subjects measured by the 36item Dental Anxiety Inventory $(13,14)$. Furthermore, Locker and Liddell (27) assessed older adults with DAS and showed that dentally anxious individuals were more likely than nonanxious ones to be edentulous. Among the dentate subjects, dentally anxious individuals had more missing and fewer filled teeth.

Bedi et al. (28) examined the DMFT (decayed, missing, and filled teeth) index among 1103 Scottish secondary school children 14 year-old. Seven percent of them had a high degree of dental anxiety. All DMFT components of the high dental anxiety children were higher than those of low or moderate dental anxiety children but only the mean MT (missing teeth) score reached statistical significance after adjustments for sex and socioeconomic class. Compared with low or moderate dental anxiety children, dentally anxious children seemed to more accurately perceive their treatment need and were more likely to defer, cancel, or not turn up for dental appointments. Furthermore, a Swedish radiographic study showed deterioration in the dental health of a group of 90 patients with severe dental fear compared 
with non-anxious dental patients (29). Self reported regular dental attendance was less in Swedes with high dental anxiety as well (3).

Many studies have supported a positive correlation between dental anxiety and compromised oral health condition. However, the generalizability of their findings were limited by the lack of non-anxious comparison groups (controls) (e.g. 19, 20), restricted study sample (e.g. 17), use of subjective rather than clinical indicators of oral health (e.g. 22, 23, 27), small sample size, specific patient groups, and/or inclusion of only patients with extreme dental fear who required specialist management (e.g. 29). The use of different instruments with different scopes of focus (30) in measuring dental anxiety may also account for some of the inconsistency in the findings.

Despite recent growing interest in the psychosocial impact of dental anxiety on daily living $(27,31)$, there is limited information on its impact on oral health-related quality of life (OHQoL). A cross-sectional study of a random sample of 300 residents in Britain revealed that dental anxiety was associated with the impact of OHQoL (32). Participants giving high scores in the psychological construct of dental anxiety were among those with worst OHQoL. A better understanding of the differences between dentally anxious and non-anxious people beyond clinical variables is important, as it gives insight into the impact of dental anxiety on people's daily living and quality of life.

The aim of this study was to investigate the relationship between dental anxiety and oral health status, as well as the impact of dental anxiety on OHQoL. Dental condition was evaluated in terms of DMFT and periodontal disease was assessed according to status of clinical attachment level (CAL). The construct of dental anxiety was measured by a comprehensive Dental Anxiety Inventory (DAxI) and OHQoL was assessed by an oral health impact questionnaire. It was hypothesized that Hong Kong dental clinic attendees with a high 
level of dental anxiety would have less favorable dental and periodontal statuses, as well as lower OHQoL, than attendees with a lower level of dental anxiety.

\section{Materials and methods}

\section{Sample}

All subjects were individuals taking part in a community study investigating the associations between psychological factors and clinical periodontal attachment level (33). That study investigated the association of stress with periodontal disease, making reference to the various components of the stress process including stressors, stress responses, coping behavior, and personality factors $(33,34)$. The study also included a clinical assessment of periodontal status, primarily the CAL, which estimated the historical amount of periodontal destruction in a given patient and DMFT, which document the caries experience of the individuals surveyed. A cross-sectional sample of 1000 subjects aged 25 to 64 years were recruited from patients attending private general dental clinics and people responding to an advertisement posted in these clinics. A set of 7 psychosocial questionnaires was used to explore the association between periodontal status and various psychological variables. Details of the community study and its recruitment procedure are described in an earlier report (33).

\section{Data collection}

The data collected in the clinical examination were used in this study and included the number of DMFT and full-mouth mean CAL. The World Health Organization (WHO) caries diagnostic criteria for DMFT were used to evaluate dental caries status (35). CAL was measured by a modified version of the procedure described by Pilgram et al. (36). The Chinese short-form version of the Oral Health Impact Profile (OHIP-14S) was used to assess 
the OHQoL $(37,38)$. This is a patient-centered outcome measure based on the WHO's "disease-impairment-disability-handicap" model. The OHIP-14S is one of the most comprehensive instruments available. It is a self-completed questionnaire consisting of 14 items subdivided into 7 domains (subscales): functional limitation, physical discomfort, psychological discomfort, physical disability, psychological disability, social disability, and handicap. These 7 conceptual domains were derived from the oral health model described by Locker (39). The instrument's psychometric properties, validity, and reliability have been assessed, and good results have been obtained $(38,40)$. Subjects were asked how frequently they had experienced negative impacts in these respects in the preceding 12 months. Responses to the items were recorded on a 5-point Likert scale: $0=$ never; $1=$ hardly ever; 2 = occasionally; 3 = fairly often; $4=$ very often. Details of the periodontal examination method and standardization and assessment of reliability are described in an earlier report (33). Calibration for measurements of CAL and DMFT was conducted in the Periodontology Clinic, Dental Faculty, The University of Hong Kong, after every 100 subjects examined (33). The Dental Anxiety Inventory - Short form (SDAxI) Chinese version was administered to measure the situation-specific trait anxiety disposition to experience anxiety in dental situations $(10,14)$. Answers were given on a 5-point Likert scale, ranging from "complete disagreement" (score, 1) to "complete agreement" (score, 5). The dental anxiety score was computed by totaling the scores of all items. The psychometric characteristics of the Chinese versions of the Dental Anxiety Inventory (DAxI) and SDAxI have appeared to be promising (10). The SDAxI offers a short, easy to complete, valid, reliable and interpretable scale for measuring dental anxiety.

\section{Data analysis}


To investigate the influence of dental anxiety on oral health condition and OHQoL, we compared individuals according to their dental anxiety level. Subjects were categorized into the following 3 groups according to their SDAxI scores: High = score of 1 standard deviation (SD) above the mean; Average = score within the range of one SD of the mean; Low $=$ score of $1 \mathrm{SD}$ below the mean. Analysis of covariance was used to examine the differences in DMFT scores, mean CAL, and OHIP-14S scores between the different dental anxiety groups after adjustment for possible confounding factors. Data were analyzed using the statistical package SPSS 12.0 (SPSS Inc., Chicago, IL). The cutoff level of significance was taken as P $=0.05$ for all tests.

\section{Ethics}

The Ethics Committee of the Faculty of Dentistry, the University of Hong Kong approved the study. All participants volunteered themselves to participate and all received comprehensive information on the study.

\section{Results}

The demographic characteristics of the study population are shown in Table 1 . The sample consisted of 53\% women and $47 \%$ men, distributed in similar ratios among all 5 age categories. Fifty-five percent of the subjects were married. Eighty-six percent of the subjects had never smoked, whereas the remaining $14 \%$ were either current or former smokers. Seventy-five percent of the study sample had received secondary school education or above. About one-third of the study sample (32.4\%) had an income above the median monthly domestic household income of the local population, which was about HK\$15,000 in 2005 (41). 
Psychometric characteristics of the SDAxI scores of the sample are shown in Table 2. Local population data are also included for reference. The Cronbach alpha coefficient for the sample was 0.81 and the item-scale correlation coefficient was between 0.91 and 0.95 .

The distributions of individuals according to level of dental anxiety by age group are shown in Table 3. Eighty percent of the subjects had SDAxI scores within the range of mean $\pm 1 \mathrm{SD}$, i.e. what was defined as average dental anxiety. The prevalence of low dental anxiety, i.e. SDAxI scores of $1 \mathrm{SD}$ below the mean, appeared similar to that of high dental anxiety, i.e. SDAxI scores of 1 SD above the mean. No statistically significant association was detected between age group and level of dental anxiety, or between reported dental attendance and dental anxiety.

CAL scores of the subjects have been reported previously (33), while DMFT scores of the different age groups are shown in Table 4. The measures of DMFT in this study were considered valid and reliable (Table 4, i.e. the relevant data were similar to corresponding values from a Hong Kong population survey), as were CAL and OHQoL, as reported previously $(33,44)$.

The mean DMFT, CAL, and OHQoL scores of the sample after adjustment for age, sex, smoking, education, income, and number of teeth are shown in Table 5. The associations between age, gender, smoking and social status on CAL; mean CAL on MT; mean CAL and number of standing teeth on oral-health related quality of life in Hong Kong subjects have been reported earlier $(33,44)$. The variance due to age, gender, smoking, education and income were first adjusted in the present study to control the possible confounding effects. As the number of missing teeth has been shown to correlate with CAL (44), the variance due to CAL was controlled in the analysis of the relation between SDAxI and MT. In analyzing the relation between SDAxI and OHIP-14S, as it has been shown that OHIP-14S correlates with 
CAL and MT (44), their possible confounding variances were also adjusted in the statistical analysis. Interaction between OHIP-14S and DT or FT was not detected.

Subjects who had higher SDAxI scores seemed to have higher DT, MT, and DMFT scores and lower FT score. The differences, however, were statistically significant only for MT, FT, and DMFT. Post hoc analysis revealed statistically significant differences in MT and DMFT between groups with high and low levels of dental anxiety, whereas statistically significant differences were found in FT across all 3 dental anxiety groups (Table 5).

The full-mouth mean CAL of the whole sample was 2.01, whereas the corresponding value for low, average, and high anxiety levels were $1.36,1.88$, and 3.59 , respectively. Subjects with higher SDAxI scores had a higher CAL; post hoc analysis detected statistical significant differences in CAL between groups with high and low levels of dental anxiety (Table 5). Similar findings were also found for the OHQoL; the mean OHIP-14S score of the whole sample was 8.26 , whereas the corresponding values for low, average, and high anxiety levels were 3.98, 8.13, and 13.17, respectively. Subjects with higher SDAxI scores had higher OHIP-14S scores - that is, a greater impact on quality of life in relation to oral health condition.

\section{Discussion}

Studies have been conducted for many years on the correlation between dental anxiety and oral health status of an individual, yet with rather inconclusive and sometimes contradictory findings $(15-18,22,23,27)$. Studies that comprehensively address the clinical impact of dental anxiety on dental problems, such as caries and periodontitis, as well as the impact on OHQoL have been limited. When clinical indicators have been used, investigators have analyzed a specific population of limited sample size (e.g. 29), failed to include a comparison group (e.g. 19, 20), or limited the study to differences in DMF status among subjects too 
young for noticeable differences to be detected (e.g. 17). As a result, some researchers have reported differences between subjects who are and are not dentally anxious (e.g. 26-28), while others have noted few, if any, differences between the 2 groups (e.g. 45).

The present study attempted to explore the impact of dental anxiety on the oral condition and OHQoL among a community population of dentate individuals who attended general dental practices. Associations between dental anxiety and the explanatory variables of decayed teeth, missing teeth, filled teeth, clinical attachment level, and score of oral health impact profile were evaluated.

\section{Sample}

The sample in the present study was of a reasonable size for evaluation of oral health conditions (c.f. 34,46$)$. Other than population representation, this cross-sectional study also ensured adequate sampling with sufficient variance in dental and periodontal conditions, dental anxiety, and OHQoL for the assessment of relationships between the explanatory and outcome variables.

Qualitatively, the study sample appeared satisfactory in terms of data describing demographic characteristics and dental and periodontal status profile, as these were similar to those of the local population $(41,46,47)$ (Table 1$)$. The size of the overall study sample and the number of subjects in subgroups remained adequate and sufficient for further statistical analysis (48). The way that subjects were recruited for the present study (33) might give an impression that only dentate subjects who were brave enough to attend a dental clinic were evaluated. However, the sampling procedure did not appear to exclude those dentate individuals with extreme dental anxiety. It was supported by the fact that SDAxI scores in the present sample were comparable to local reference data (10). 


\section{$S D A x I$}

An instrument measuring dental anxiety should be able to measure proneness to anxiety and predict the anxiety state of an individual when he or she is actually facing a dental situation. Dental anxiety is a complicated phenomenon and its multifactorial nature is very often undermined in its measuring instruments $(13,30)$. Dentally anxious subjects are not a homogeneous group of people and they differ in various aspects, including the etiology of fear and its manifestation in terms of affective, behavioral, and cognitive reactions (49). A review has suggested that different aspects of dental anxiety should be included in a measurement instrument - namely, the situation to which it pertains, the reactions it evokes, and its duration (30). The DAS (21) and the Dental Fear Survey (DFS) (50), being 2 wellknown instruments, fail to address this multifactorial dimension (51). The DAxI is based on facet theory $(52,53)$, thereby offering a useful heuristic approach in the construction of measurement instruments for multifactorial concepts and enabling the DAxI to specify an exhaustive and systematic description and definition of the complex phenomenon of dental anxiety. The facet approach also obviously offers added value on the level of operationalization for measurement of dental anxiety (10).

The original DAxI was in Dutch and was subsequently translated into English $(6,54)$. In order to make use of this instrument to measure the dental anxiety of Chinese in Hong Kong, translation and validation were necessary. The construct validity, discriminant validity, reliability, and internal consistency of the Chinese DAxI and its short form (SDAxI) have been substantiated (10). The DAxI not only identifies extremely anxious dental patients, but also manages to assess anxiety proneness in regular dental patients and the prevalence of dental anxiety in the general population $(13,14,51)$.

The validity of the SDAxI as used in the present study was empirically supported, as the results were comparable with local norms $(10,55)$. The high Cronbach alpha coefficient 
and item-scale correlation coefficient (Table 2) also indicated that items used in the SDAxI measured a common factor and had a reasonably satisfactory convergent validity when applied in the present sample of subjects. It is noteworthy, however, that the SDAxI score of 21.3 or above in the high dental anxiety group seemed lower than scores for other populations $(8,51)$. This difference remains compatible with local reference data and can probably be explained by cultural differences (10).

\section{DMFT and CAL}

Because the effects of oral diseases are cumulative over time, the clinical indicators selected should be able to reflect concisely and objectively the overall picture of the general population. In the present study, the DMFT index and full-mouth mean CAL were used as estimates of the cumulative dental impact as well as of the historical amount of periodontal destruction in a given patient (56). The findings presented here suggest that dentate, dentally anxious subjects had more missing teeth, fewer filled teeth, and more periodontal attachment loss than low dental anxiety subjects (Table 5). By using clinical indicators of DMFT, this study was more objective than previous studies (15-18). This was also probably the first ever study to focus on the relationship between dental anxiety and periodontal status in a general population. Results of this study showed a statistically significant association between dental anxiety and periodontal status $(F=3.37, P=0.035)$ (Table 5).

This community study shed light on several issues about dental anxiety. Firstly, dental anxiety correlates with poor dental and periodontal health. This finding is intuitively supported and consistent with human psychology in that the disposition to experience anxiety in dental situations leads to avoidant behaviors and, in turn, delays in receiving adequate preventive care or treatment. In addition, neglect of oral health leads to increased pain, more stress, and further avoidance. The vicious cycle so established may be further enhanced by 
memories of past distressing experiences (57). However, it is also possible that poor dental health, necessitating repeated dental treatments, contributes to bad experiences and so to heightened anxiety; the likely direction of the association remains unclear. Secondly, highly dental anxious individuals or those with a high SDAxI have significantly more MT, fewer FT, and a similar number of DT when compared with those with a low SDAxI (Table 5). Individuals with high dental anxiety may have a compromised dental condition due to avoidance. They may resort to more definitive and less complex treatment than root treatment, crowns, and bridge work when they have to seek treatment for pain, swelling, or other conditions. This preference may be due to avoidance in staying in the dental chair/clinic for the long time necessary for these treatments, and/or dentists' unwillingness to treat patients with high levels of dental anxiety. These notions are consistent with the finding that individuals with high dental anxiety have more missing teeth than those who are not anxious. However, results of the current study contrast with the reported observation that the dentition of dentally anxious people remains largely unrestored (27).

\section{$O H Q o L$}

This study represents one of the first attempts to explore the relationship between dental anxiety, oral health status, and OHQoL. Quality of life is increasingly acknowledged as a valid, appropriate, and significant indicator of service need and intervention outcomes in contemporary public health research and practice. Health-related quality of life measures, including objective and subjective assessments, are especially useful for evaluating efforts to prevent disabling chronic diseases and their effectiveness (58). Assessing the consequences of impaired oral health from the patient's perspective has emerged as an important research area (59). This has in turn lead to an increase in the use of patient-centered oral health status measures, primarily those attempting to measure the impact of OHQoL (60). 
Dental anxiety was found to have a statistically significant association with OHQoL $(F=3.58, P=0.028)$ after adjustment for the effects of age, sex, smoking, education, income, number of teeth present, and full-mouth mean CAL. This association may exist because dentally anxious people may avoid dental care to such a degree that their oral health condition becomes significantly compromised beyond merely dental and periodontal conditions and their daily living becomes affected to a considerable extent. This explanation echoes the findings of McGrath and Bedi (32) that dental anxiety in Britain is associated with the impact that oral health has on life quality and that people who experience high levels of dental anxiety are among those with the poorest OHQoL. The explanation is also plausible, given the evidence that dentally anxious people have poor oral health, tend to delay treatment, and resort to more definitive and less conservative care than non-anxious people. A longitudinal study, however, is required to substantiate the above hypothesis.

In conclusion, dental anxiety contributes to poor periodontal and dental health as well as compromised OHQoL. In treatment of dental and periodontal diseases, especially severe or refractory cases, dental anxiety and subsequent avoidance and neglect behaviors should be properly addressed so as to facilitate and enhance the intervention process and outcome. It has also been generally accepted that dentally anxious individuals are not a homogeneous group, as they differ in the origins and manifestations of their anxiety about dental treatment $(61,62)$. Adequate understanding of dental anxiety is necessary to allow dentists to provide appropriate and effective treatment $(4,54,63)$. In spite of research in the past few decades, several cardinal issues concerning dental anxiety have still not been properly answered. For example, little is known about the etiological pathways that lead to the development of dental anxiety, its incidence at different points in life, and its course over time. Further study investigating the facets of dental anxiety and oral health would be necessary to give a more precise picture. Attention and resources should then be allocated for identifying and 
managing dentally anxious people and to enable them to maintain a better oral health condition and hence enjoy a better quality of life.

\section{Acknowledgements}

The work described in this paper was substantially supported by a grant from the Research Grants Council of the Hong Kong Special Administrative Region, China (HKU 7331/00M). 


\section{References}

1. Green RM, Green A. Adult attitudes to dentistry among dental attenders in South Wales. Br Dent J 1985;159:157-60.

2. Stouthard ME, Hoogstraten J. Prevalence of dental anxiety in The Netherlands. Community Dent Oral Epidemiol 1990;18:139-42.

3. Hakeberg M, Berggren U, Carlsson SG. Prevalence of dental anxiety in an adult population in a major urban area in Sweden. Community Dent Oral Epidemiol 1992;20: 97-101.

4. Moore R, Birn H, Kirkegaard E, Brodsgaard I, Scheutz F. Prevalence and characteristics of dental anxiety in Danish adults. Community Dent Oral Epidemiol 1993;21:292-6.

5. Vassend O. Anxiety, pain and discomfort associated with dental treatment. Behav Res Ther 1993;31:659-66.

6. Skaret E, Raadal M, Berg E, Kvale G. Dental anxiety among 18-yr-olds in Norway. prevalence and related factors. Eur J Oral Sci 1998;106:835-43.

7. Schwarz E, Birn H. Dental anxiety in Danish and Chinese adults - a cross-cultural perspective. Soc Sci Med 1995;41:123-30.

8. Maggirias J, Locker D. Five-year incidence of dental anxiety in an adult population. Community Dent Health 2002;19:173-9.

9. Smith TA, Heaton LJ. Fear of dental care: are we making any progress? J Am Dent Assoc $2003 ; 134: 1101-8$

10. Ng SKS, Stouthard MEA, Leung WK. Validation of a Chinese version of Dental Anxiety Inventory. Community Dent Oral Epidemiol 2005;33:107-14.

11. Edelmann RJ. Anxiety: theory, research, and intervention in clinical and health psychology. Chichester: John Wiley and Sons Ltd.; 1992.

12. Lautch H. Dental phobia. Br J Psychiatry 1971;119:151-8. 
13. Stouthard ME, Mellenbergh GJ, Hoogstraten J. Assessment of dental anxiety: a facet approach. Anxiety Stress Coping 1993;6:89-105.

14. Stouthard ME, Hoogstraten J, Mellenbergh GJ. A study on the convergent and discriminant validity of the Dental Anxiety Inventory. Behav Res Ther 1995;33:589-95.

15. Gale E, Ayer W. Treatment of dental phobias. J Am Dent Assoc 1969;78:1304-7.

16. Schuurs AHB, Duivenvoorden HJ, Thoden van Velzen SK, Verhage F. Three factors predicting irregular versus regular dental attendance: a model fitting to empirical data. Community Dent Oral Epidemiol 1980;8:413-9.

17. Cohen ME. Dental anxiety and DMFS status: association within a US naval population versus differences between groups. Community Dent Oral Epidemiol 1985;13:75-8.

18. Woolgrove J, Cumberbatch G, Gelbier S. Understanding dental attendance behaviour. Community Dent Health 1987;4:215-21.

19. Berggren U, Meynert G. Dental fear and avoidance: causes, symptoms, and consequences. J Am Dent Assoc 1984;109:247-51.

20. Molin C, Seeman K. Disproportionate dental anxiety. Clinical and nosological considerations. Acta Odontol Scand 1970;28:197-212.

21. Corah NL. Development of a dental anxiety scale. J Dent Res 1969;48:596.

22. Milgrom P, Fiset L, Melnick S, Weinstein P. The prevalence and practice management consequences of dental fear in a major US city. J Am Dent Assoc 1988;116:641-7.

23. Locker D, Liddell A. Correlates of dental anxiety among older adults. J Dent Res 1991;70:198-203.

24. Schuurs AH, Duivenvoorden HJ, Thoden van Velzen SK, Verhage F, Eijkman MA, Makkes PC. Sociodemographic correlates of dental anxiety. Community Dent Oral Epidemiol 1985;13:212-5. 
25. Locker D, Liddell A, Burman D. Dental fear and anxiety in an older adult population. Community Dent Oral Epidemiol 1991;19:120-4.

26. Stouthard ME, Hoogstraten J. Dental anxiety: a comparison of dentate and edentulous subjects. Community Dent Oral Epidemiol 1990;18:267-8.

27. Locker D, Liddell A. Clinical correlates of dental anxiety among older adults. Community Dent Oral Epidemiol 1992;20:372-5.

28. Bedi R, Sutcliffe P, Donnan P, Barrett N, McConnachie J. Dental caries experience and prevalence of children afraid of dental treatment. Community Dent Oral Epidemiol 1992;20:368-71.

29. Hakeberg M, Berggren U, Grondahl HG. A radiographic study of dental health in adult patients with dental anxiety. Community Dent Oral Epidemiol 1993;21:27-30.

30. Schuurs AHB, Hoogstraten J. Appraisal of dental anxiety and fear questionnaires: a review. Community Dent Oral Epidemiol 1993;21:329-39.

31. Cohen SM, Fiske J, Newton JT. The impact of dental anxiety on daily living. Br Dent J. 2000;189:385-90.

32. McGrath CM, Bedi R. The association between dental anxiety and oral health-related quality of life in Britain. Community Dent Oral Epidemiol 2004;32:67-72.

33. Ng SKS, Leung WK. A community study on the relationship between stress, coping, affective dispositions and periodontal attachment loss. Community Dent Oral Epidemiol 2006;34:252-66.

34. Genco RJ, Ho AW, Grossi SG, Dunford RG, Tedesco LA. Relationship of stress distress and inadequate coping behaviors to periodontal disease. J Periodontol 1999;70:711-23.

35. World Health Organization. Dentition status and treatment needs. In: Oral health surveys: basic methods, $4^{\text {th }}$ Ed. pp. 40-7. Geneva: World Health Organization; 1997. 
36. Pilgram TK, Hildebolt CF, Yokojama-Crothers N, Dotson M, Cohen SC, Hauser JF et al.. Relationships between radiographic alveolar bone height and probing attachment level: data from healthy post-menopausal women. J Clin Periodontol 2000;27:341-6.

37. Slade GD, Spencer AJ. Development and evaluation of the Oral Health Impact Profile. Community Dent Health 1994;11:3-11.

38. Wong MC, Lo EC, McMillan AS. Validation of a Chinese version of the Oral Health Impact Profile (OHIP). Community Dent Oral Epidemiol 2002;30:423-30.

39. Locker D. Measuring oral health: a conceptual framework. Community Dent Health 1988;5:3-13.

40. Slade GD. Derivation and validation of a short-form oral health impact profile. Community Dent Oral Epidemiol 1997;25:284-90.

41. Census and Statistics Department of the HKSAR. Hong Kong Annual Digest of Statistics. HKSAR: The Printing Department; 2005.

42. Tobacco control office. Hong Kong smoking prevalence. Hong Kong SAR: Department of Health; 2005. Available at: http://www.tobaccocontrol.gov.hk/eng/loadframe.html?id=102.

43. Dental Service Head Office. Oral health survey 2001: common dental diseases and oral health related behaviour. Hong Kong SAR: Department of Health; 2002.

44. Ng SKS, Leung WK. Oral health-related quality of life and periodontal status. Community Dent Oral Epidemiol 2006;34:114-22.

45. Stabholz A, Peretz B. Dental anxiety among patients prior to different dental treatments. Int Dent J 1999;49:90-4.

46. Holmgren CJ, Corbet EF, Lim LP. Periodontal conditions among the middle-aged and the elderly in Hong Kong. Community Dent Oral Epidemiol 1994;22:396-402. 
47. Lo ECM, Schwarz E. Tooth and root conditions in the middle-aged and the elderly in Hong Kong. Community Dent Oral Epidemiol 1994;22:381-5.

48. Schwarz E, Lo EC. Dental health knowledge and attitudes among the middle-aged and the elderly in Hong Kong. Community Dent Oral Epidemiol 1994;22:358-63.

49. Locker D, Liddell A, Shapiro D. Diagnostic categories of dental anxiety: a populationbased study. Behav Res Ther 1999;37:25-37.

50. Kleinknecht RA, Klepac RK, Alexander LD. Origins and characteristics of fear of dentistry. J Am Dent Assoc 1973;86:842-8.

51. Stouthard ME. Angst voor de tandheelkundige behandeling. (Dental Anxiety.) Thesis Amsterdam: University of Amsterdam; 1989. (in Dutch).

52. Canter D. Facet theory. New York: Springer Verlag; 1985.

53. Roskam EECI, Broers NJ. Constructing questionnaires: An application of facet design and item response theory to the study of lonesomeness. In: Engelhard G, Wilson M (eds.), Objective measurement: Theory into practice, pp. 349-85. Norwood: Ablex; 1996.

54. Aartman IH, de Jongh A, Makkes PC, Hoogstraten J. Dental anxiety reduction and dental attendance after treatment in a dental fear clinic: a follow-up study. Community Dent Oral Epidemiol 2000;28: 435-42.

55. China Association of Mental Health. Rating scales for mental health. Beijing: Chinese Mental Health Journal; 1993. (in Chinese).

56. Cohen BH, Lea RB. Essentials of statistics for the social and behavioral sciences. Hoboken NJ: Wiley; 2004.

57. Eli I. Oral psychophysiology: stress, pain, and behaviour in dental care. Florida: CRC Press; 1992.

58. Hennessy CH, Moriarty DG, Zack MM, Scherr PA, Brackbill R. Measuring health-related quality of life for public health surveillance. Public Health Rep 1994;109:665-72. 
59. Buck D, Newton JT. Non-clinical outcome measures in dentistry: publishing trends 198898. Community Dent Oral Epidemiol 2001;29:2-8.

60. Birch S, Ismail AI. Patient preferences and the measurement of utilities in the evaluation of dental technologies. J Dent Res 2002;81:446-50.

61. Milgrom P, Weinstein P, Kleinknecht R, Getz T. Treating fearful dental patients: a patient management handbook. Reston, Virginia: Reston Pub. Co.; 1985.

62. Thomson WM, Locker D, Poulton R. Incidence of dental anxiety in young adults in relation to dental treatment experience. Community Dent Oral Epidemiol 2000;28:289-94.

63. Zuniga JR. Guidelines for anxiety control and pain management in oral and maxillofacial surgery. J Oral Maxillofac Surg 2000;58:4-7. 
Table 1. Demographic characteristics of subjects ${ }^{\mathrm{a}}$

\begin{tabular}{|c|c|c|c|}
\hline \multirow[b]{2}{*}{ Demographic characteristics } & \multicolumn{2}{|c|}{ Sample } & \multirow{2}{*}{$\begin{array}{l}\text { Population } \\
(\%)\end{array}$} \\
\hline & $n$ & $\%$ & \\
\hline \multicolumn{4}{|l|}{$\operatorname{Sex}^{\mathrm{b}}$} \\
\hline Male & 469 & 46.9 & $48.5^{\mathrm{c}}$ \\
\hline Female & 531 & 53.1 & $51.5^{\mathrm{c}}$ \\
\hline \multicolumn{4}{|l|}{ Age in years ${ }^{b}$} \\
\hline 25 to 34 (male : female, $44.5 \%: 55.5 \%$ ) & 292 & 29.2 & $28.2^{\mathrm{c}}$ \\
\hline 35 to 44 (male : female, $48.2 \%: 51.8 \%$ ) & 355 & 35.5 & $34.6^{\mathrm{c}}$ \\
\hline 45 to 54 (male : female, $48.9 \%: 51.1 \%$ ) & 233 & 23.3 & $24.4^{\mathrm{c}}$ \\
\hline 55 to 64 (male : female, $45.0 \%: 55.0 \%$ ) & 120 & 12.0 & $12.8^{\mathrm{c}}$ \\
\hline \multicolumn{4}{|l|}{ Ethnicity ${ }^{\mathrm{b}}$} \\
\hline Chinese & 955 & 95.5 & $94.9^{c}$ \\
\hline Others & 45 & 4.5 & $5.1^{\mathrm{c}}$ \\
\hline \multicolumn{4}{|l|}{ Marital status ${ }^{\mathrm{b}}$} \\
\hline Never married & 350 & 35.0 & $31.9^{\mathrm{c}}$ \\
\hline Married & 550 & 55.0 & $59.4^{\mathrm{c}}$ \\
\hline Separated/divorced/widowed & 100 & 10.0 & $8.7^{\mathrm{c}}$ \\
\hline \multicolumn{4}{|l|}{ Smoking ${ }^{\mathrm{b}}$} \\
\hline None & 860 & 86.0 & $82.9^{\mathrm{d}}$ \\
\hline Very light ( $>0$ to 5.2 pack-years) & 11 & 1.1 & NA \\
\hline Light (5.3 to 15.0 pack-years) & 39 & 3.9 & NA \\
\hline Moderate (15.1 to 30.0 pack-years) & 35 & 3.5 & NA \\
\hline Heavy (> 30.0 pack-years) & 55 & 5.5 & NA \\
\hline \multicolumn{4}{|l|}{ Education ${ }^{\mathrm{b}}$} \\
\hline None/preschool & 38 & 3.8 & $3.8^{\mathrm{c}}$ \\
\hline Primary & 213 & 21.3 & $21.4^{\mathrm{c}}$ \\
\hline Secondary & 576 & 57.6 & $48.0^{\mathrm{c}}$ \\
\hline Tertiary or above & 173 & 17.3 & $26.8^{\mathrm{c}}$ \\
\hline \multicolumn{4}{|l|}{ Monthly household income (in HK\$) } \\
\hline$<\$ 14,999$ & 613 & 66.8 & $68.1^{\mathrm{c}}$ \\
\hline$\$ 15,000-\$ 29,999$ & 233 & 25.4 & $23.8^{\mathrm{c}}$ \\
\hline$>\$ 30,000$ & 72 & 7.8 & $8.2^{\mathrm{c}}$ \\
\hline \multicolumn{4}{|l|}{ Occupation $^{\mathrm{b}}$} \\
\hline Manager/administrator & 88 & 8.8 & NA \\
\hline Professional/associate professional & 131 & 13.1 & NA \\
\hline Clerk/sales/services section & 58 & 5.8 & NA \\
\hline Housewife & 62 & 6.2 & NA \\
\hline Retired & 55 & 5.5 & NA \\
\hline Student & 130 & 13.0 & NA \\
\hline Unemployed/other & 1 & 0.1 & NA \\
\hline Others & 475 & 47.5 & NA \\
\hline \multicolumn{4}{|l|}{ Dental care $^{\mathrm{b}}$} \\
\hline Regular & 249 & 24.9 & $26.3^{\mathrm{g}}$ \\
\hline Irregular & 751 & 75.1 & $73.7^{\mathrm{g}}$ \\
\hline
\end{tabular}


$\mathrm{NA}=$ not available.

${ }^{a}$ Please refer to $\mathrm{Ng} \&$ Leung (33) for detailed description of the subject demographic data.

${ }^{\mathrm{b}} n=1000$.

${ }^{c}$ Population reference data is from Hong Kong Census and Statistic Department (41).

${ }^{\mathrm{d}}$ Population reference data (2003) is from Tobacco Control Office (42); daily cigarette smokers: $14.4 \%$, ex-daily cigarette smokers: $2.7 \%$.

${ }^{\mathrm{e}} \mathrm{US} \$ 1.00=\mathrm{HK} \$ 7.80$.

${ }^{\mathrm{f}} n=918 ; 82$ subjects refused to disclose income details.

${ }^{\mathrm{g}}$ Population reference data for dental care pattern is from Oral Health Survey 2001 (43). 
Table 2. Psychometric characteristics according to the Chinese SDAxI

\begin{tabular}{lll}
\hline & $\begin{array}{l}\text { SDAxI } \\
(n=1,000)\end{array}$ & Population $^{\mathrm{a}}$ \\
\hline Mean \pm SD & $15.81 \pm 5.51$ & $15.20 \pm 6.00$ \\
Range & $9-39$ & $9-40$ \\
Internal consistency - Cronbach alpha & 0.81 & 0.80 \\
Item-scale correlation coefficient & $0.91-0.95$ & $0.91-0.94$ \\
\hline
\end{tabular}

${ }^{a}$ Population reference data is from $\mathrm{Ng}$ et al. (10). 
Table 3. Levels of dental anxiety according to age group

\begin{tabular}{|c|c|c|c|c|}
\hline \multirow{2}{*}{$\begin{array}{l}\text { Age } \\
\text { (year) }\end{array}$} & \multirow[b]{2}{*}{$n$} & \multicolumn{3}{|c|}{ Levels of dental anxiety $^{a}$} \\
\hline & & Low & Average & High \\
\hline $25-34$ & 292 & $8.6 \%)^{b}$ & $234(80.1 \%)$ & $33(11.3 \%)$ \\
\hline $35-44$ & 355 & $9.9 \%)$ & $279(78.6 \%)$ & $41(11.5 \%)$ \\
\hline $45-54$ & 233 & $9.9 \%)$ & $189(81.1 \%)$ & $21(9.0 \%)$ \\
\hline $55-64$ & 120 & $13(10.8 \%)$ & $97(80.8 \%)$ & $10(8.3 \%)$ \\
\hline Overall & 1000 & $96(9.6 \%)$ & $799(79.9 \%)$ & $105(10.5 \%)$ \\
\hline
\end{tabular}

Chi-square statistic, $\chi^{2}=2.273, P>0.05$.

${ }^{a}$ Levels of dental anxiety: Low - SDAxI score $<10.03$; average - SDAxI score 10.03 to 21.3; high - SDAxI score $>21.3$.

${ }^{\mathrm{b}}$ Prevelance as compared to the same age group. 
Table 4. Mean decayed, filled, missing, DMFT scores according to age group

\begin{tabular}{llllll}
\hline Age (year) & $n$ & $\mathrm{D}$ & $\mathrm{F}$ & $\mathrm{M}$ & DMFT \\
\hline $25-34$ & 292 & 0.62 & 2.05 & 3.92 & 6.59 \\
$35-44^{\mathrm{a}}$ & 355 & 0.75 & 2.51 & 4.43 & 7.69 \\
$45-54$ & 233 & 0.92 & 3.89 & 7.96 & 12.77 \\
$55-64$ & 120 & 1.04 & 2.91 & 9.93 & 13.88 \\
Total & 1000 & 0.79 & 2.75 & 5.76 & 9.30 \\
\hline
\end{tabular}

${ }^{a}$ Similar to corresponding data from the Hong Kong Oral Health Survey 2001 $\overline{(43) ; 35-44 \text { age }}$ group: D/F/M/DMFT: 0.7/2.8/3.9/7.4. 
Table 5. Adjusted scores ${ }^{\mathrm{a}}$ (mean $\pm \mathrm{SD}$ ) of dental and periodontal variables and oral health-related quality of life, by level of dental anxiety

\begin{tabular}{|c|c|c|c|c|c|c|c|c|c|c|c|}
\hline \multirow[b]{3}{*}{ SDAxI scores } & \multicolumn{8}{|c|}{ Levels of Dental Anxiety } & \multirow[b]{2}{*}{$F$ statistic } & \multirow[b]{2}{*}{$\begin{array}{l}\text { Significance } \\
(P \text {-value })\end{array}$} & \multirow[b]{2}{*}{$\begin{array}{l}\text { Post hoc } \\
\text { analysis }\end{array}$} \\
\hline & \multicolumn{2}{|c|}{$\begin{array}{l}\text { Low } \\
(n=96)\end{array}$} & \multicolumn{2}{|c|}{$\begin{array}{l}\text { Average } \\
(n=799)\end{array}$} & \multicolumn{2}{|c|}{$\begin{array}{l}\text { High } \\
(n=105)\end{array}$} & \multicolumn{2}{|c|}{$\begin{array}{l}\text { Overall } \\
(n=1000)\end{array}$} & & & \\
\hline & 9.62 & \pm 0.36 & 15.02 & \pm 2.47 & 27.44 & \pm 4.31 & 15.81 & \pm 5.51 & 4.68 & 0.001 & $1<2<3$ \\
\hline DT & 0.72 & \pm 0.97 & 0.78 & \pm 0.93 & 0.93 & \pm 0.95 & 0.79 & \pm 0.94 & 2.51 & 0.082 & \\
\hline MT & 4.09 & \pm 3.89 & 5.82 & \pm 5.51 & 6.83 & \pm 5.91 & 5.76 & \pm 5.49 & 3.81 & 0.023 & $1<3$ \\
\hline FT & 3.67 & \pm 2.27 & 2.73 & \pm 1.89 & 2.02 & \pm 1.92 & 2.75 & \pm 1.98 & 3.72 & 0.025 & $1>2>3$ \\
\hline DMFT & 8.48 & \pm 2.98 & 9.33 & \pm 5.21 & 9.78 & \pm 3.12 & 9.3 & \pm 4.51 & 3.13 & 0.042 & $1<3$ \\
\hline CAL & 1.36 & \pm 0.31 & 1.88 & \pm 0.29 & 3.59 & \pm 0.56 & 2.01 & \pm 0.94 & 3.37 & 0.035 & $1<3$ \\
\hline OHIP-14S & 3.98 & \pm 2.57 & 8.13 & \pm 9.95 & 13.17 & \pm 7.21 & 8.26 & \pm 10.07 & 3.58 & 0.028 & $1<2<3$ \\
\hline
\end{tabular}

${ }^{\mathrm{a}}$ Adjusted for age, sex, smoking, education, and income; for MT further adjusted for CAL; for OHQoL further adjusted for full-mouth mean CAL and MT; ANOVA.

${ }^{b}$ Levels of dental anxiety: Low $=$ SDAxI score $<10.03$; average $=$ SDAxI score 10.03 to 21.3; high $=$ SDAxI score $>21.3$.

${ }^{\mathrm{c}}$ Post hoc analysis by Tukey's HSD tests, groups 1, 2 and 3 refer to low, average, and high dental anxiety, respectively. 